\title{
Some aspects of the long-term effects of malnutrition on the behaviour of children in the Third World
}

\author{
BY J, PAGET STANFIELD \\ 25 Brandling Place South, Jesmond, Newcastle upon Tyne NE2 4RU
}

My subject appears on the face of it a very straightforward matter of relating the effect of one variable, a previous period of malnutrition, on another, behaviour of children in the Third World. The more I have struggled to review our own and many others' attempts to do just this, the more difficult the task has become. My own experience has familiarized me with malnutrition, as it so terribly and unnecessarily afflicts infants and children in the Third World and in particular in Africa. This experience has raised an initial question which I have had to deal with in addressing the subject and to which I will come back later.

Undernutrition in developing countries is almost inevitably associated with the poverty syndrome. The poverty syndrome embraces the condition of health associated with poverty or lack, not only of food, but of stimulation, education, resources, etc. The question facing those concerned with its effects is, can the outcome of poverty of nutrients in such situations be identified and isolated? Still more fundamentally, does the isolation of specific nutritional effects really matter? For the remedy of such poverty inevitably requires a programme combining enrichment of nutrition with enrichment of the quality of life and environment for the child, the mother, the family and the community.

There are justifications for more clearly outlining the poverty syndrome, its ingredients and its outcomes. It is vital to know to what extent each ingredient is responsible for not only immediate morbidity and mortality but also for long-term handicap.

Furthermore the balance of these ingredients of poverty as they contribute to its outcome is important, as well as their relationships and interactions with each other. Within malnutrition itself there may be periods when the supply of some nutrients becomes critical for the proper growth and development of a particular organ or tissue. There are within the spectrum of malnutrition deficiencies of nutrients, such as for example iodine in the production of thyroxine, which can retard or prevent nervous system development. Toxic elements may accumulate which could severely and organically damage brain substance. These need to be known and not remain hidden.

I am going to concentrate on protein-energy malnutrition (PEM) as it affects the early life of the infant and child, and as it forms the major nutrient deficiency syndrome throughout the Third World. Two lines of observation have raised concern about the long-term consequences of malnutrition in early childhood in the Third World. With the recognition of PEM as a major determinant of illness and death, attention was drawn to the similarity of its clinical and behavioural manifestations to severe deprivation of the sort which has permanent behavioural sequelae in children in the Developed World. At about the same time attention was focused on the long-term effects of malnutrition as a result of early studies on growth in animals. The discovery that 'catch-up' growth in animals could be permanently impaired when nutritional inadequacy occurred during a critical period coinciding with the most rapid growth and development of the brain 
caused considerable concern (Dobbing, 1974; Winick, 1976). Failure to 'catch up' was found to be associated with permanent impairment of brain size, neuronal numbers and synapses and myelinization together with neurological and behavioural deficits. The pathology in these animals, refed after early malnutrition, resembled rather a failure of development and maturation than actual neuronal damage and death. Whatever the nature of the process the question arose, does it occur and what is the nature of its outcome in man?

In the human situation malnutrition and deprivation are so deeply interwoven within the poverty syndrome that any consideration of ultimate consequences must include their immediate character and manifestations.

In the first place, it is important to be as fully aware as possible of the character of malnutrition as it occurs in the Third World so as to gain insight into the complex factors bound up in the poverty syndrome. Each and every one of these may be partly responsible for any longer-term effects on behaviour and development.

First, there are many different antecedents of malnutrition. In any given community, those families and even individual children at risk of malnutrition can often be predicted (Cravioto \& Delicardie, 1972; Goodall, 1979). Goodall (1979) developed a social score for predicting kwashiorkor in Ugandan children on the basis of a number of disadvantages such as socio-economic, family break up, single mothers, depressed mothers, orphans, short birth spacing, low birth weight, separation at weaning, especially if abrupt as so often occurs when the mother becomes pregnant again (Geber \& Dean, 1955). The antecedent history of the malnourished child is a litany of disadvantage which is depriving the infant before he or she becomes malnourished. Malnutrition is often the 'straw that breaks the camel's back'.

Second, malnutrition has no very definable duration. The eclipse by PEM does not necessarily afflict the child suddenly nor does it depart suddenly. Periods of acute clinical malnutrition often alternate with periods of marginal normality often related to freedom from infection or an availability of food and clean water. Often malnutrition is seasonal. The dietary intake may be sufficient to maintain centiles of growth and development when there is no added stress, but insufficient to regain a previous centile after an infection or a hungry period. So the disadvantaged child steps deeper into chronic undernutrition by failing to achieve an adequate rehabilitation 'catch up' and may remain thus for most, if not all, the growing years.

Third, malnutrition is associated with periods of reduced activity, apathy and illness often accompanied by hospital admission at a time when a normal child is growing, learning and developing faster than at any other time of life. Such eclipse of movement, exploration, motivation, communication and stimulation resembles the state of 'functional isolation' described in malnourished animals by Levitsky et al. (1975). The normal ordered pattern of growth and development is distorted and may be very difficult to regain during a rehabilitation which may in itself be imbalanced or incomplete. How long does such complete or partial eclipse need to continue before the delay becomes irretrievable? Can disordered behaviour and development for age regain their proper order?

Fourth, malnutrition has a human face, an individuality. One malnourished child differs from another according to his genetic potential for growth, intelligence, temperament, and ability to adapt. He lives within an environmental microcosm in which operate all the facets of human life under stress. Malnutrition affecting a child interacts with the 
mother, the family, the community and the environment. The mother's or the carer's reaction may be to accept the loss of interplay between herself and her malnourished child. She may be thankful he or she is so little a burden to her. Thus, neglect and secondary deprivation develop. Graves $(1976,1978)$ on the other hand described increased contact between mother and child as part of increased concern, perhaps even of guilt over her child's condition. This will increase the child's dependency and reduce his exploration. The mother is depressed because of her child's, and very often her own, malnutrition. This depression may antecede the child's malnutrition and be a reaction to her own poverty and inability to cope. She may become fatalistic. She, herself, may be 'functionally isolated' and may often have little more energy or motivation than to sit and nurse the child. In areas where malnutrition and resultant mortality are common a child is often rejected or not named until he or she reaches an age when he or she is likely to survive, and this happens with girls more often than with boys in some cultures. These social interactions have effects on children which have scarcely been measured.

Finally the malnutrition syndrome may differ in each child with regard to the nutrient deficits, the complications of infections, toxaemias, iatrogenic or traditional treatments and the possibilities of different genetic susceptibilities and potentials. Energy and protein are the basic deficits. Hidden within the PEM spectrum there are often deficits of other micronutrients such as iron and other metallic elements, vitamins, etc. which may only reveal themselves when growth is recommenced, such as for instance in vitamin D and folic acid deficiency. There is still no agreement as to whether oedematous kwashiorkor and wasting marasmus are two ends of a continuum. One current view is that kwashiorkor is a toxaemia triggered by infection and due to accumulation of free oxide radicals (Golden, 1988). Infections may be occult and chronic and exert their own influence. Treatment, hospitalization and traditional remedies may give rise to morbidity with its own long-term disability.

Thus, the single factor, malnutrition, in the human situation is seen to be an amalgam of many different ingredients each of which may act and interact in their effects and each of which need to be identified as far as possible in the study of longer-term morbidity, particularly in the selection of control groups.

In the second place the immediate manifestations of PEM on infant and childhood behaviour and development are obvious and often severe. In its early and mild phases the child adapts to a declining food intake. It is very difficult to determine when this adaptation becomes damaging or pathological. Any necessity to adapt may have a deleterious effect. Inactivity as a result of energy restriction is occurring at an age when exploration of the environment is so vital for normal development. Reduction of activity is accompanied by reduction of growth which can continue for a remarkably long time. Head circumference participates in this and the question arises as to what this signifies in terms of the brain which has also been found to weigh less in children dying with PEM (Brown, 1965).

Electroencephalographic (EEG) changes have been reported (Barnet et al. 1978). A so-called neurological recovery syndrome is described, the 'kwashi-shakes' (Kahn, 1954). I have seen such tremors accompanied by other transient neurological symptoms such as an oculogyric attack suggestive of basal ganglia involvement in the recovery stage of acute kwashiorkor. Behaviour-wise there is nothing so miserable or so heart rending as a child with acute malnutrition. The gaze in such a child's eyes, hurt, sad and hopeless has been described, in acutely deprived infants in the Developed World, as the 'radar' 
gaze (Goodall, 1979). These children look through you focused on infinity and they epitomize the state of so-called 'functional isolation'. It is similar to the look of frozen watchfulness described by Ounsted et al. (1974) in physically deprived or abused children. Apathy and regressive changes in development and behaviour increase; the child adopts an almost fetal position, clinging to mother, and crying in a pattern and manner similar to brain-damaged children (Galler, 1984). In less severe malnutrition the child's attention becomes much less sustainable with irritability and increased dependency on the mother. When children like these are compared with normal children of their age it is not surprising if considerable prolonged detriment was to follow.

At this stage I may briefly mention the investigation Dr Jan Hoorweg and I conducted in 1970 at the British Medical Research Council's Infantile Malnutrition Research Unit (IMRU) in Kampala, Uganda. We made use of the opportunity this unit presented to answer the question of whether the shadow of an attack of acute clinical PEM in early childhood, as it presented in rural Uganda, could be detected during the teenage years, about 11-15 years later. The unit had operated from 1953 and had kept meticulous records of all the infants admitted acutely malnourished and also many children not clinically malnourished but seen and followed up in a rural clinic some 12 miles north of Kampala. Weights were charted, health, nutritional status and home environment recorded and a detailed account kept of how to reach their homes such that up to 16 years later we were able to trace over $90 \%$ of them. The previously malnourished children, sixty in number were divided into three groups of twenty depending on the age at admission (8-15, 16-21 and 22-27 months of age). They were matched individually with each of the malnourished groups and a fourth non-malnourished group of twenty children whose weight-for-age had never fallen below the Harvard tenth centile (Stuart \& Stevenson, 1954). All the children came from one area of Buganda, were of the same tribe and matched for age, sex, education and home environment. They were examined between 11 and 17 years of age. We found that the three previously malnourished groups fell significantly (but not profoundly) below the comparison group in anthropometry (height, weight and head circumference) and in tests of intellectual and motor abilities (Hoorweg \& Stanfield, 1976). Their current nutritional and health status were similar. The results showed a general impairment of intellectual abilities with reasoning and spatial abilities most affected; memory and learning by rote moderately and language ability least affected. No correlation was found between these differences and age at admission. There were significant correlations with the degrees to which the children had been underweight or marasmic on admission but none with the degrees to which they had shown features of acute kwashiorkor, i.e. oedema, skin changes and serum protein deficit. We concluded that the long-term outcome of malnutrition was the outcome of long-term malnutrition in the sense that the presence of acute kwashiorkor changes did not seem to exert any long-term influence.

These results were similar to many other Third World study conclusions, whether prospective or retrospective, completed at about the same period (Stoch \& Smythe, 1967; Champakam et al. 1968; Birch, 1972; Hertzig et al. 1972). Malnutrition within the context of growing up in the Third World was associated with impairment of intellectual abilities of a long-standing nature. Under the conditions of life as they continued to surround these children there was incomplete 'catch up' in achievement despite, in many of the studies, complete 'catch up' in nutritional status when compared with their non-malnourished controls. None of the studies could satisfactorily disentangle the 
nutrient deficits from the possible environmental disadvantages through which these children had passed. These were largely unidentifiable and unmeasurable both in index and control children, and might still have been operating at the time of study.

At about the same time the results of several studies from the Developed World began to emerge. These showed that malnutrition associated with disease in infancy and early childhood (pyloric stenosis, coeliac disease, fibrocystic disease, etc.) was not associated on the whole with any long-term effects on intellect or development (Berglund \& Rabo, 1973; Lloyd-Still et al. 1974; Valman, 1974; Ellis \& Hill, 1975; Klein et al. 1975; Beardslee et al. 1982). Either malnutrition on its own in infancy and childhood had exerted no permanent irrecoverable deficit, or in the absence of other deprivations or the presence of a total balanced rehabilitation, its effect had been counteracted.

The generation of studies coming to fruition in the 1980s have shifted the emphasis of enquiry from intellectual achievement to include the whole behavioural development of the child. They have also attempted to improve the measure and, thus, the control of the complex independent co-variables associated with malnutrition and establish more predictable, specific and measurable indicators of behavioural outcome. To accomplish the first of these, that is to measure more carefully the concomitants of malnutrition, a number of prospective studies were launched in which different interventions were applied to malnourished groups or groups at risk of becoming malnourished. Some of these were commenced in early pregnancy to cover if possible the critical period of growth of the central nervous system. I know of no studies which preceded conception.

Those studies which I have been able to examine carefully (Galler, 1987; GranthamMcGregor, 1987; Sinisterra, 1987), on the whole, have confirmed that the intellectual and behavioural deficits associated with undernutrition as it occurs in the Developing World have persisted in spite of varying 'catch up' which depended on the quality, quantity, persistence and comprehensiveness of the rehabilitation. Grantham-McGregor et al. (1991) recently reported that food supplementation and psychosocial stimulation each provided a beneficial effect in terms of improved development compared with a control group of children. The effect was additive in a group of children who received both; a result which was interpreted as showing that each had had an independent effect, but which is scarcely surprising. The intervention studies which have included pregnancy do not show any marked variation in the differences, between index and control groups, from those commenced in early infancy (Chavez et al. 1975; Waber et al. 1981; Barratt et al. 1982; Joos et al. 1983; Barratt, 1986). This is not surprising as supplementation in pregnancy has had only small effects on birth weight even at very low energy intake (Prentice et al. 1983). It would appear that the fetus is protected against the effects of protein-energy deficits by the mother herself, except in so far as they are accompanied by specific nutrient deficits such as certain vitamins or elements, I or Fe. The long-term effects of low birth weight, which have hardly as yet been studied in the Developing Country environment, are more likely to be due to placental insufficiency, in turn due to many other influences apart from malnutrition.

Patterns of behavioural distortion have been identified into late adolescence and senior school age-groups (Barratt, 1986; Galler, 1987; Galler \& Ramsey, 1989; Galler et al. 1990). They have been predicted from those which present concurrently or in the short-term aftermath of PEM and resemble closely the effects described in the literature on the 'deprivation' syndrome. They centre on poorer academic performance associated with poorer attention-span, persistence and memory, with resultant greater distract- 


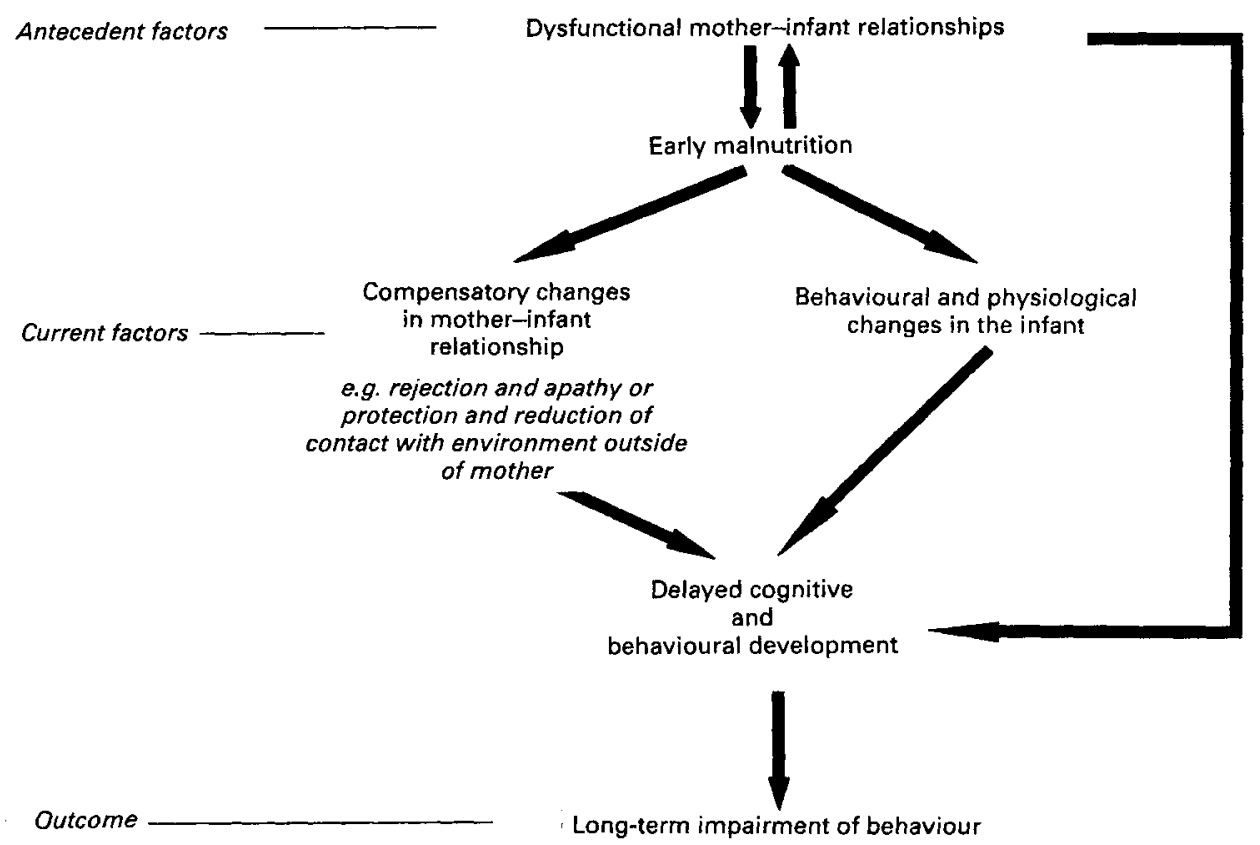

Fig. 1. Relationship between early malnutrition and behavioural impairment (modified from Galler et al. 1984).

ability. The affected children show conduct disorders with less ability to cope with frustration and to control impulses. The 'functional isolation' characteristic of concurrent malnutrition is still detectable in the tendency to withdraw from involvement in class initiatives especially when activity is at its most competitive; in fearfulness and in reduced interest, curiosity, exploration and responsiveness. All these behavioural components are interrelated.

Supplementation studies by Barratt et al. (1982) seemed to indicate that cognitive function was much less affected by supplementation, particularly energy supplementation of undernourished mothers and children, than behaviour. They suggested that later behavioural disturbances were related to the adaptation a child had to make in the face of chronic undernutrition which removes or insulates him from the environment. Malnutrition's main impact on early human life is to deprive it of the means of learning and relating normally to life. Galler et al. (1984) described a relationship between early malnutrition and behavioural impairment as shown in Fig. 1.

There are still disagreements as to the importance and place of early malnutrition as compared with socio-economic deprivation in the natural history of reduced potential (Richardson et al. 1978). There are also disagreements as to the degree of handicap such reduced potential really represents. On the one extreme Chavez \& Martinez (1979) describe the resultant timid, insecure, dependent child as destined to live in filth, to inactivity and to resignation. On the other hand Stoch et al. (1982) were able to state that their group of disadvantaged children, acutely malnourished during infancy and followed up for 20 years had integrated effectively into the community. Though retarded in mental development, compared with a less-disadvantaged and non-malnourished control group, 


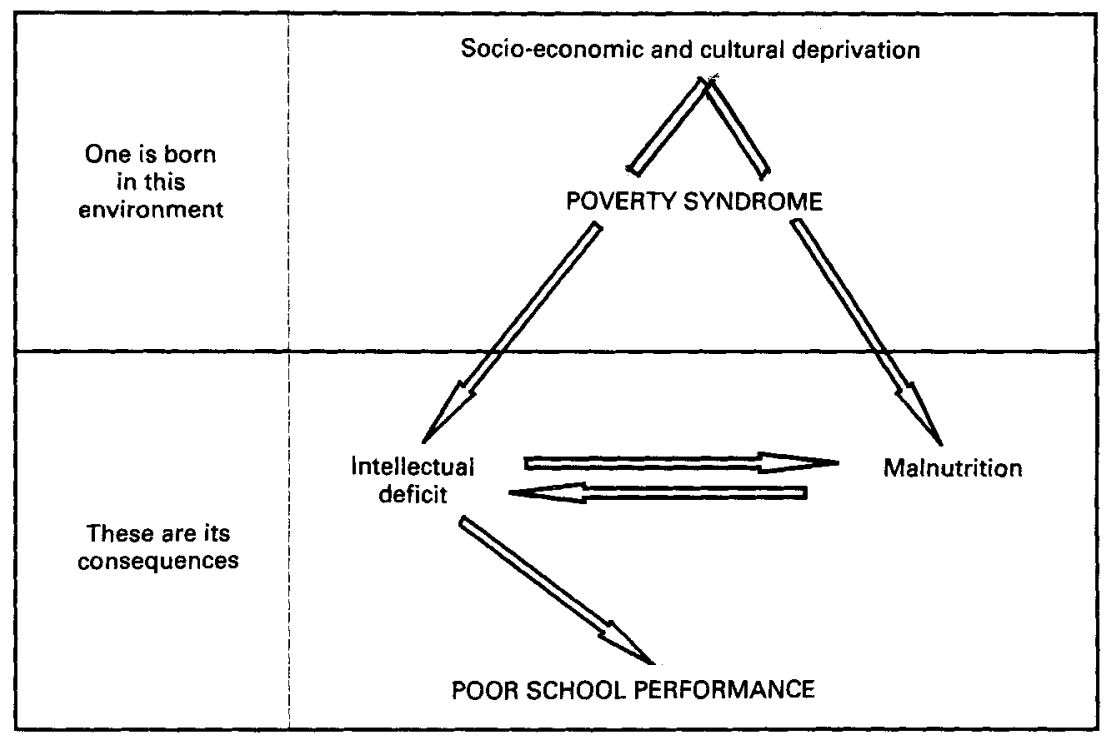

Fig. 2. The poverty syndrome and its consequences (modified from Schuftan, 1984).

their behaviour was not one of insecurity. Some of them, with children of their own, were caring for them much better than they had been cared for themselves and were living in much better conditions than their parents.

There is still no consensus on the place of early malnutrition among the many possible determinants of the outcomes emerging from all these studies. Winick (1987) considers the question still unanswered, 'Are the behavioural changes . . . demonstrated . . . in humans the result only of the previous undernutrition or is the whole environment in which malnutrition is occurring responsible for those changes?' Richardson (1987) considers the evidence from the studies thus far does not indicate that severe malnutrition in infancy results in permanent and severe mental impairment for the individual. Schuftan (1984) in an earlier paper considers that malnutrition and cultural deprivation are not the ultimate causes of poor performance of school-age children, although they may be part of the more immediate cause. He concludes that poverty as reflected in low socio-economic and educational status of families underlies the poor school performance as shown in Fig. 2.

One observation in all these studies which has not been sufficiently emphasized is that the differences between previously malnourished and non-malnourished children are small compared with the differences between disadvantaged children (whether they have passed through a period of malnutrition or not) and normally privileged middle class children within the same Third World countries. This surely indicates that there are influences causing far greater detriment to the disadvantaged child, as compared with the optimally healthy child growing up in the same country, than have so far been revealed. Studies into the effects of PEM have revealed the nature and magnitude of the long-term detriment it carries, but there seems to me to be no further point in trying to separate disadvantage into its components of which malnutrition is but one indicator of its severity. The emphasis should be changed to deprivation and malnutrition as outcomes 
of much more profound stresses and disadvantage within the poverty syndrome. The nature of these as they affect nutritional status, behaviour and achievement need to be examined much more carefully at community-based level as they affect mother, child and family. These disadvantages may well have generational detriment. Secular trends seem to move towards not only increasing height but also to improved achievement as communities become less disadvantaged. At the same time likely remedies implemented by the community can be studied for their effectiveness in ameliorating at least the worst effects of the poverty syndrome (Williams, 1973).

More study is required of the longer-term effects of specific nutrient deficiencies, including those in pregnancy, on the achievement of children. We know that $\mathrm{Fe}$ deficiency in pregnancy is a cause of low birth weight and its aftermath. I deficiency (but how widespread?) is a major cause of hypothyroidism and mental retardation. Vitamin A deficiency causes blindness and vitamin $\mathrm{B}$ deficiencies cause neurological syndromes.

Finally one of the long-term effects of malnutrition, and the poverty syndrome as a whole, as it affects children in the Developing World should be to influence our own behaviour. It should convict us of the responsibility we have in the Developed World for the scenario in which malnutrition and deprivation is occurring in the Third World. It must also constrain us to utilize our knowledge and convictions to persuade the world community to remove those burdens for which we are responsible, such as the debt burden and trade protectionism, and to assist in a much more understanding relationship with Third World communities so that they can break out from the poverty cycle in which they are presently trapped.

\section{REFERENCES}

Barnet, A. B., Weiss, I. P., Sotillo, M. V., Ohrlich, E. S., Sakurovich, Z. M. \& Cravioto, J. (1978) . Abnormal auditory evoked potentials in early infancy malnutrition. Science 201, 450-452.

Barratt, D. E. (1986). Nutrition and social behavior. In Theory and Research in Behavioral Pediatrics, chap. 4 [H. E. Fitzgerald. B. M. Lester and M. W. Yogman, editors]. New York: Plenum Press.

Barratt, D. E., Radke-Yarrow, M. \& Klein, R. E. (1982). Chronic malnutrition and child behaviour: effect of early calorie supplementation on social-emotional functioning at school age. Developmental Psychology18, 541-556.

Beardslee, W. R., Wolff, A. H., Hurwitz, I., Parikh, B. \& Schwachman, H. (1982). The effects of infantile malnutrition on behavioural development: a follow up study. American Journal of Clinical Nutrition 35, 1437-1441.

Berglund, G. \& Rabo, E. (1973). A long term follow up investigation of patients with hypertrophic pyloric stenosis with special reference to the physical and mental development. Acta Paediatrica Scandinavica 62, 125-129.

Birch, H. G. (1972). Malnutrition, learning and intelligence. American Journal of Public Health 62, 773-784.

Brown, R. E. (1965). Decreased brain weight in malnutrition and its implications. East African Medical Journal 42, 584-595.

Champakam, S., Srikantia, S. G. \& Gopalan, C. (1968). Kwashiorkor and mental development. American Journal of Clinical Nutrition 21, 844-852.

Chavez, A. \& Martinez, C. (1979). Behavioral effects of undernutrition and food supplementation. In Proceedings of the International Nutrition Conference; Behavioral Effects of Energy and Protein Deficits, p. 216. Washington, DC: US Department of Health, Education and Welfare.

Chavez, A., Martinez, C. \& Yaschine, T. (1975). Nutrition,-behavioural development and mother-child interactions in young rural children. Federation Proceedings 34, 1574-1582.

Cravioto, J. \& Delicardie, E. R. (1972). Environmental correlates of severe clinical malnutrition and language development in survivors from kwashiorkor or marasmus. In Nutrition, the Nervous System and Behavior. Proceedings of the Seminar on Malnutrition in Early Life and Subsequent Mental Development. PAHO Document no. 251, pp. 73-94. Washington, DC: Pan American Health Organization. 
Dobbing, J. (1974). The later development of the brain and its vulnerability. In Scientific Foundation of Paediatrics [J. A. Davis and J. Dobbing, editors]. London: Heinemann Medical.

Ellis, C. E. \& Hill, D. E. (1975). Growth, intelligence and school performance in children with cystic fibrosis who have had an episode of malnutrition during infancy. Journal of Pediatrics 87, 565-568.

Galler, J. R. (editor) (1984). Behavioral consequences of malnutrition in early life. In Human Nutrition, vol. 5, pp. 63-117. New York and London: Plenum Press.

Galler, J. R. (1987). The interaction of nutrition and environment on behavioural development. In Early Nutrition and Later Achievement, pp. 175-207 [J. H. Dobbing, editor]. London: Academic Press.

Galler, J. R. \& Ramsey, F. R. (1989). A follow up study of the influence of early malnutrition on development: behavior at home and at school. Journal of the American Academy of Child and Adolescent Psychiatry 28, 254-261.

Galler, J. R., Ramsey, F. R., Morley, D. S., Archer, E. \& Salt, P. (1990). The long-term effects of early kwashiorkor compared with marasmus. IV. Performance on the National High School entrance examinations. Pediatric Research 28, 235-239.

Galler, J. R., Ricciuti, H. N., Crawford, M. A. \& Kucharski, L. T. (1984). Mother-infant interactions in nutritional disorders. In Human Nutrition, vol. 5, pp. 283-304 [J. R. Galler, editor]. New York and London: Plenum Press.

Geber, M. \& Dean, R. F. A. (1955). Psychological factors in the aetiology of kwashiorkor. Bulletin of the World Health Organization 12, 471-475.

Golden, M. (1988). The effects of malnutrition in the metabolism of children. Transactions of the Royal Society of Tropical Medicine and Hygiene 82, 3-6.

Goodall, J. (1979). A social score for kwashiorkor: explaining the look in the child's eyes. Developmental Medicine and Child Neurology 21, 374-384.

Grantham-McGregor, S. (1987). Field studies in early nutrition and later achievement. In Early Nutrition and Later Achievement, pp. 128-174 [J. H. Dobbing, editor]. London: Academic Press.

Grantham-McGregor, S. M., Powell, C. A., Walker, S. P. \& Hines, J. H. (1991). Nutritional supplementation, psychosocial stimulation and mental development of stunted children: the Jamaican study. Lancet 338, 1-5.

Graves, P. L. (1976). Nutrition, infant behaviour and material characteristics, a pilot study in West Bengal, India. American Journal of Clinical Nutrition 29, 305-319.

Graves, P. L. (1978). Nutrition and infant behaviour: a replication study in the Katmandu valley, Nepal. American Journal of Clinical Nutrition 31, 541-551.

Hertzig, M. E., Birch, H. G., Richardson, S. A. \& Tizard, J. (1972). Intellectual levels of school children severely malnourished during the first two years of life. Pediatrics 49, 814-824.

Hoorweg, J. \& Stanfield, J. P. (1976). The effects of protein energy malnutrition in early childhood on intellectual and motor abilities in later childhood and adolescence. Developmental Medicine and Child Neurology 13, 330-350.

Joos, S. K., Pollitt, E., Mueller, W. H. \& Albright, D. L. (1983). The Bacon Chow study: maternal nutrition supplementation and infant behavioural development. Child Development 54, 669-676.

Kahn, E. (1954). A neurological syndrome in infants recovering from malnutrition. Archives of Diseases in Childhood 29, 256-261.

Klein, P. S., Forbes, G. B. \& Nadar, P. R. (1975). Effects of starvation in infancy (pyloric stenosis) on subsequent learning abilities. Journal of Pediatrics 87, 8-15.

Levitsky, D. A., Massaro, T. F. \& Barnes, R. H. (1975). Maternal malnutrition and the neonatal environment. Federation Proceedings 34, 1583-1586.

Lloyd-Still, J. D., Hurwitz, I., Wolff, P. H. \& Schwachman, H. (1974). Intellectual development after severe malnutrition in infancy. Pediatrics 43, 306-311.

Ounsted, C., Oppenheimer, R. \& Lindsay, J. (1974). Aspects of bonding failure. Developmental Medicine and Child Neurology 16, 447-456.

Prentice, A. M., Whitehead, R. G., Watkinson, M., Lamb, W. H. \& Cole, T. (1983). Prenatal dietary supplementation of African women and birth weight. Lancet $\mathrm{i}, 489-492$.

Richardson, S. A. (1987). Discussion on field studies in nutrition and achievement. In Early Nutrition and Later Achievement, p. 159 [J. H. Dobbing, editor]. London: Academic Press.

Richardson, S. A., Koller, H., Katz, M. \& Albert, K. (1978). The contributions of differing degrees of acute and chronic malnutrition in the intellectual development of Jamaican boys. Early Human Development 2 , 163-170.

Schuftan, C. (1984). Low school performance: malnutrition or cultural deprivation. In Malnutrition and Behaviour: Critical Assessment of Key Issues, pp. 389-395 [J. Brozek and B. Schurch, editors]. Lausanne: Nestlé Foundation. 
Sinisterra, L. (1987). Studies on poverty, human growth and development: the Cali experience. In Early Nutrition and Later Achievement, pp. 208-244 [J. H. Dobbing, editor]. London: Academic Press.

Stoch, M. B. \& Smythe, P. M. (1967). The effect of undernutrition during infancy on subsequent brain growth and intellectual development. South African Medical Journal 41, 1027-1030.

Stoch, P. S., Smythe, P. M., Moodie, A. D. \& Bradshaw, D. (1982). Psychosocial outcome and C.T. Findings after gross undernourishment during infancy: a 20 year developmental study. Developmental Medicine and Child Neurology 24, 419-436.

Stuart, H. C. \& Stevenson, S. S. (1954). Physical growth and development. In Textbook of Pediatrics, 6th ed., pp. 10-66 [W. E. Nelson, editor]. Philadelphia: Saunders.

Valman, H. B. (1974). Intelligence after malnutrition caused by neonatal resection of the ileum. Lancet i, 425-427.

Waber, D. P., Vuori-Christiansen, L., Ortiz, N., Clement, J. R., Christiansen, N. E., Mora, J. O., Reed, R. B. \& Herrera, M. G. (1981). Nutritional supplementation, maternal education and cognitive development of infants at risk of malnutrition. American Journal of Clinical Nutrition 34, 807-813.

Williams, C. D. (1973). Health services in the home. Pediatrics 52, 773-781.

Winick, M. (1976). Nutrition and cellular growth of the brain. In Malnutrition and Brain Development, pp. 63-97. New York: Oxford University Press.

Winick, M. (1987). Editorial: Long term effects of kwashiorkor. Journal of Pediatric Gastroenterology and Nutrition 6, 833-835. 